\title{
The childbearing experience of women with spinal cord injury in Iran: a phenomenological study
}

\author{
Zahra Khazaeipour $^{1} \cdot$ Alireza Nikbakht-Nasrabadi ${ }^{1,2} \cdot$ Nooredin Mohammadi $^{3}$ Alireza Salehi-Nejad $\mathbb{1}^{4,5}$. \\ Maryam Shabany $\mathbb{B}^{1}$
}

Received: 16 October 2017 / Revised: 16 May 2018 / Accepted: 17 May 2018 / Published online: 14 June 2018

(C) International Spinal Cord Society 2018

\begin{abstract}
Study design This was a qualitative study conducted using an interpretative phenomenological approach.

Objectives This study investigated the experience of pregnancy and childbirth in women with spinal cord injury (SCI). Setting Brain and Spinal Cord Injury Research Center, Tehran University of Medical Sciences, Tehran, Iran.

Methods The data were collected using telecommunication and face-to-face semi-structured interviews with eight women with SCI. The study employed the interpretative phenomenological approach suggested by Van Manen in 2016 and thematic analysis to provide a comprehensive understanding of the childbearing experience of women with SCI. MAXQDA 10 software was used to manage the collected data.

Results Five main themes have emerged from data analysis: "revivification", "fear and concern of motherhood with SCI", "flawed health care system", "maternal experience under a supportive umbrella", and "strengthening spirituality and religious belief".

Conclusion Childbearing had a positive effect on the family relationship, continuity of marriage, and quality of life following SCI. There are potential benefits in establishing a center that provides consultation on childbearing and childcare for women with SCI. Moreover, training for the medical team, which includes nurses, midwives, and specialists is highly recommended. Further research is needed to expand our understanding of childbearing from the perspectives of healthcare providers.
\end{abstract}

\section{Introduction}

After a steady decline in maternal and perinatal mortality rates, childbirth has become a more significant experience for women [1]. In fact, pregnancy and childbirth are normal

Maryam Shabany

maryamshabanyi@yahoo.com

1 Brain and Spinal Cord Injury Research Center, Neuroscience Institute, Tehran University of Medical Sciences, Tehran, Iran

2 Department of Medical Surgical Nursing and Deputy Dean for International Affairs, Nursing and Midwifery School, Tehran University of Medical Sciences, Tehran, Iran

3 Department of Critical Care Nursing, Nursing and Midwifery School, Iran University of Medical Sciences, Tehran, Iran

4 Faculty of World Studies, University of Tehran, Tehran, Iran

5 International Association of Communication in Healthcare, Tehran University of Medical Sciences, Tehran, Iran physiological processes, and an important and exciting occurrence in the lives of many women and their families [2]. Overall, for some women, childbirth is a positive and valuable experience; however, for others, it can be considered as a negative experience $[2,3]$.

It is worth noting that culture is one of the factors that can affect the experience of childbearing and motherhood; hence, women from different cultural backgrounds may share a different experience in this regard [4]. In Iranian religious and cultural norms, childbearing is considered as a valuable occasion and it is regarded as one of the obligations of a married woman [4]. Similarly, Iranian women recognize childbearing as a great source of emotional, social, and economic support over their life course [4].

The holistic experience of pregnancy and childbirth in women is an important issue to understand [5]. The quality of these experiences, the health of mother and child, their emotional relationship, sexual activity, and desire for having another child may affect a woman's life in the future [6]. 
One of the factors that may significantly affect a woman's childbearing experience could be her specific disability. In fact, women with different types and forms of disability have different concerns about childbirth [7].

Given the relatively high prevalence rate of spinal cord injury (SCI) in Iran, it can be considered as an important form of disability [8]. According to the World Health Organization, an estimated 250,000-500,000 people suffer from SCI every year in the world, which imposes considerable costs on individuals and society [9]. A substantial number of people with SCI are young women, who are at the age of fertility and capable of pregnancy and childbirth [10].

Several studies have shown that pregnancy may affect different aspects of quality of life and women with SCI may experience psychological and physical complications. As an example, pregnant women with SCI are more likely to experience mood swings and depression than those without disabilities $[11,12]$. In addition, they may experience further physical complications such as urinary tract infections, anemia, and autonomic dysreflexia - a condition identified through the sudden onset of excessively high blood pressure, pain, severe headaches, bradycardia, flushing, and sweating [13-15].

Due to the limited research literature in Iran and other countries, understanding the childbearing experience of women with SCI is rather difficult. Thus, both quantitative and qualitative studies are necessary for further comprehension of this phenomenon. Such research could help to improve the quality of care before, during and after childbirth in this group of women [16]. Hence, this study was designed with the purpose of comprehending the lived experience of women with SCI regarding pregnancy and childbirth.

\section{Methods}

\section{Study design}

An interpretative phenomenological analysis (IPA) was employed to describe and interpret the childbearing experience in mothers with SCI.

\section{Methodology}

Interpretive phenomenology is a part of the family of phenomenological psychology approaches, which adopt an holistic qualitative approach. The interpretative phenomenological analysis aims to understand and determine the new meanings of a personal lived experience that has previously gone unrecognized, and it offers the opportunity to gain an understanding of the meaning of a phenomenon as it really is for the individual [17, 18]. Hence, this approach reveals the hidden meanings of the phenomenon under study [18]. The findings of phenomenological studies can provide a more detailed understanding of the phenomenon, and subsequently provide evidence for improving health care practice [19]. As such, the interpretive phenomenological analysis was deemed appropriate for this study, and prompted the researchers to focus on the individual lived experience of women under study [20].

\section{Participants}

Eight women with SCI, who had the post-injury experience of childbearing and were referred by the SCI Association of Tehran, participated in this study. The inclusion criteria for participants included having an SCI, being Iranian, Persianspeaking women (more than 18 years of age); who had successfully given birth to healthy children within the past 10 years and were willing to participate in this study by sharing their experience.

The Director of the SCI Association of Tehran introduced each of the eight women in the study to the researchers.

\section{Data collection}

This research was conducted during the period of December 2016 to March 2017, and the data was collected using indepth semi-structured interviews [21].

Initially, the researchers explained the purpose of the research to the participants through telephonic communications and invited them to participate in this study. All eight women, who were contacted, agreed to participate in this research. Four of the participants came to the Brain and Spinal Cord Injury Research Center in-person and were interviewed face-to-face in a private room at the Center. The other four participants opted for telephone interviews due to a number of reasons such as the discomfort of an in-person interview, being away from the Brain and SCI Research Center, having transportation problems, having symptoms of physical conditions (such as pain and spasms), and time scarcity to attend the interview in-person.

The relevant medical documents of the participants at the SCI Association were accessed with their written permission and were used to complete Table 1. The scheduled interviews comprised open-ended, nondirective questions, and included main and follow-up questions. In addition, exploration questions were used for the in-depth interviews and the participants were requested to provide further explanations by giving examples [22, 23]. Examples of the interview questions are shown in Table 2. A process of reflecting and probing was adopted to ensure that each participant directed the content of her interview. The researchers requested further clarifications to ensure the 
Table 1 Participants' information

\begin{tabular}{|c|c|c|c|}
\hline \multicolumn{2}{|l|}{ Variables } & \multirow[t]{2}{*}{$N$} & \multirow{2}{*}{$\begin{array}{l}\text { Median } \\
\text { (interquartile range) }\end{array}$} \\
\hline Age range (year) & $29-47$ & & \\
\hline \multicolumn{4}{|l|}{ Cause of injury } \\
\hline Earthquake & & 1 & \\
\hline Car accident & & 7 & \\
\hline \multicolumn{4}{|l|}{ Education } \\
\hline Primary school & & 3 & \\
\hline Secondary school & & 3 & \\
\hline College & & 2 & \\
\hline $\begin{array}{l}\text { Duration of marriage range } \\
\text { (years) }\end{array}$ & $3-20$ & & $14.5(11.5-16.5)$ \\
\hline \multicolumn{4}{|l|}{ Level of SCI } \\
\hline $\mathrm{T} 7$ & & 1 & \\
\hline $\mathrm{T} 8$ & & 1 & \\
\hline T9 & & 1 & \\
\hline T12 & & 3 & \\
\hline L1 & & 2 & \\
\hline \multicolumn{4}{|l|}{ Type of SCI lesion } \\
\hline Complete & & 8 & \\
\hline Incomplete & & 0 & \\
\hline $\begin{array}{l}\text { Range of length of time } \\
\text { since SCI (years) }\end{array}$ & $6-34$ & & $14(8-23)$ \\
\hline \multicolumn{4}{|l|}{ Type of birth ${ }^{\mathrm{a}}$} \\
\hline Cesarean section & & 7 & \\
\hline Vaginal & & 1 & \\
\hline \multicolumn{4}{|l|}{ Type of anesthesia } \\
\hline General & & 6 & \\
\hline Spinal & & 0 & \\
\hline \multicolumn{4}{|c|}{ Number of children before SCI } \\
\hline 0 & & 6 & \\
\hline 1 & & 1 & \\
\hline 2 & & 11 & \\
\hline \multicolumn{4}{|l|}{ Number of children after SCI } \\
\hline 1 & & 5 & \\
\hline 2 & & 3 & \\
\hline $\begin{array}{l}\text { The age range of the first } \\
\text { child after SCI (years) }\end{array}$ & Newborn-13 & & \\
\hline $\begin{array}{l}\text { The age range of the } \\
\text { second child after } \mathrm{SCI}^{\mathrm{b}} \\
\text { (years) }\end{array}$ & $6-8$ & & \\
\hline
\end{tabular}

${ }^{a}$ Related to the last childbirth

${ }^{\mathrm{b}}$ Only two of the women with SCI had a second child

correct interpretation of the participants' statements. The sequence of questions for each interview was rather unique, and depended on the interview process and the answers provided by the interviewee [23]. Each interview was conducted in $\sim 45-120 \mathrm{~min}$. Finally, the interviews were recorded, transcribed ad verbatim, and then coded.
Table 2 Examples of the interview questions

Main questions:

1) How did you feel when you found out that you were pregnant?

2) What changed in your life after your pregnancy?

3) What pleasant experience do you have about childbirth?

Follow-up questions:

1) What caused the pregnancy to be a pleasant event?

2) How significant are the changes in your life?

Exploration question:

1) Would you give an example about an unpleasant experience?

\section{Data analysis}

The corresponding author (MS) employed holistic and narrow approaches for the extraction of data and themes, recommended by Van Manen [24]. In the holistic approach, after reading the transcript several times, a general understanding of the participant's experience was obtained from each interview; then, the meaning and concepts of the text were described as a whole in one or more paragraphs. In the narrow method, each of the interviews was read separately, and each of the phrases and sentences was carefully studied; then, the keywords and concepts were marked based on their significance and in accordance with the research question [25].

The researcher considered the research questions throughout the data analysis process as a necessity of the interpretive phenomenological approach. The focus on the question (what is the experience of women with SCI through pregnancy and childbirth?) in the mind of the researcher resulted in the extraction of themes and interpretations. In order to facilitate the analysis, the MAXQDA 10 was also used.

\section{Rigor considerations}

According to the process described in a review article by Krefting, in order to determine the validity of the research [26], the findings of this study were presented to the participants for review and confirmation of the content. Then, the participants expressed their views on the coordination of the findings with their experiences of pregnancy and childbirth. The findings of the study were also discussed during meetings with specialists and experts.

In addition, the peer review of two methodology experts [ANN and NM] and their perspectives on the interpretation of the findings were used to increase the credibility [27].

The long-term involvement of the researcher by allocating adequate time for data collection had helped to gain the trust of participants, a factor that is essential to increase the 
credibility. In addition, for ease of confirmability, the documentation related to the study is retained and archived [27].

\section{Results}

All the participants were paraplegic. The mean (SD) age of the participants was 36.12 (6.87), and the mean (SD) length of time since their SCI was 16 (9.42) years. In addition, the mean (SD) duration of the marriage was 13.5 (5.01) and the participants had not had the history of an abortion or miscarriage. Selected medical information of the participants is in Table 1 .

In the present study, the five main themes that emerged from data analysis included "revivification", "fear and concern of motherhood with SCI", "flawed health care system", "maternal experience under a supportive umbrella", and "strengthening spirituality and religious belief". It should be noted that pseudonyms were used to protect the participants' identities.

\section{Revivification}

For the women in the study, childbearing has provided revivification with enhancement of their own life and improvement in their marital life. Accordingly, the related sub-themes have been described as follows:

\section{A feeling of incredible joy}

Some of the participants in this research stated that their pregnancy was unplanned, as they were not aware that they could become pregnant. Since these women become pregnant years after their SCI, they were ecstatic for this incredible event. It was reported that this happiness led to an inner freshness and vitality.

"During the pregnancy, every time that someone [would have] said, "“you are pregnant", it triggered a joy in my heart, and [to me and my husband] it was like we could have a family like everyone else. Despite the difficulties that I had during the pregnancy, it is such a good feeling to see your child is growing, and it is just unbelievable." (Susan)

Some women with SCI spoke about the happiness of their husbands:

"My husband was also so happy, as if it was his first child, although, we have two grown-up sons." (Sara)

Moreover, the women with SCI reported about the happiness and surprise of their relatives, who had not expected their pregnancy.
"[My relatives] were all surprised that I'm pregnant. They did not expect my pregnancy; but, they were happy and congratulated me with such a great surprise. My relatives were astonished on the grounds that my pregnancy was impossible due to my disability." (Roxana)

\section{An encouragement for life}

All the participants considered childbearing as an encouragement to live. They stated that childbearing has influenced their life plans and hopes, and it has been a positive event in their lives.

"Now, we think about the future and make plans, since our hope to live has increased. We did not speak too much about the future plans, but now, we are hopeful" (Elmira)

Most participants indicated that the experience was an enhancement to their husband's life:

"My husband took care of our baby very well. The child rekindled him in life. It's like something good has been happening. I do not mean that he was hopeless, but now, it seems that our lives have become warmer and we are happier." [sic] (Mona)

\section{The feeling of equality}

The feelings of the participants were rather varied regarding fertility. As an example, one participant reported that the family of her husband believed that a woman with SCI is sexually inactive; however, after the childbirth, they changed their perception and had an understanding that women with SCI can give birth. It was reported that this experience has placed them on an equal footing.

"Since the time I gave birth, I feel that I am similar to healthy people, we can have a family, and I am not different than others." (Sara)

\section{The improvement and the continuity of marriage}

In the interview, the participants noted improvement and continuity of marriage after childbirth. For a number of them, giving birth had an important role in strengthening their marital life. In some of the families, a dominant culture, which views women as reproduction machines, was 
reported; hence, the post-SCI childbearing has led to the continuity of marriage.

"I feel that life is much sweeter now because I had many conflicts with my husband before bearing a child. [My husband's] family wanted him to remarry since they longed to have many [grand] children. They assumed I could not get pregnant again, but now they are not talking about remarriage anymore." (Sara)

\section{Completion of the marriage by childbirth}

Some of the participants considered childbirth as an important factor for having a complete marriage, and this was something that they had been told by their families.

\begin{abstract}
"My family told me that one of the reasons they let me get married was to have a child. I have been told that marriage is complete with having children (she laughs). Honestly, before having children, I had not been a housewife to take care of my husband, and he let me do whatever I wanted, so I was not at home most of the time. I did not feel that I was married; but, after the childbirth everything has changed, and I stay home more often." (Susan)
\end{abstract}

\section{Fear and concern of motherhood with $\mathrm{SCI}$}

The fear and concern of motherhood were something that women with SCI felt from pregnancy until childbirth.

\section{Concerns about unpleasant pregnancy outcomes}

All the women with SCI experienced the concern of miscarriage in the present study.

"I had always thought that I could not have a healthy pregnancy, and I might have a stillborn baby." (Elmira)

Birth defects were among other major concerns.

"I had feared the child might become hunched or bowed [anormal] since I was always sitting." (Aida)

\section{The fear of physical complications during pregnancy}

The participants were concerned about the potential negative impacts of pregnancy on their physical health. It is worth noting that some of the participants had a history of surgery in the femur, and one had cystoplasty (transplantation of the small intestine to the bladder). They reported a little fear and concern about the physical complications of childbirth.

"When I found out that I was pregnant, I was not happy at first. I was afraid that the pregnancy might worsen my situation." (Susan)

\section{False alarms provoked by others}

A number of participants mentioned that their relatives had reportedly provoked concerns about the baby's health, and these judgments led to unhappiness and depression.

"My relatives used to say that: "wwe know healthy people who had considerable childbirth difficulties, and we do not think that you can do this"'. I had been told that I might suffer a miscarriage or genetic defects. These words made me cry in loneliness, and I got slightly depressed." (Aida)

\section{Fear of being a mother with disabilities}

Some of the participants were concerned that their disability may prevent taking care of their children adequately and noted possible limitations in childcare.

"My child was going under the wheelchair, and it was so difficult to turn around and grab his hands to lift him up. The paralyzed legs make a mother so limited. I was always worried that he might fall down the stairs and I could not do anything about it." (Leila)

\section{Flawed health care system}

Some of the participants had bad memories about their childbirth, and some had experienced difficulty; nonetheless, almost all participants had some common issues related to the health care providers.

\section{Inappropriate professional ethics}

A small number of participants were dejected about the inappropriate behavior of health care providers, including indifference to the opinions of the patients and verbal abuses.

"My water broke before childbirth, and I was afraid, so I went to the nearest hospital in which I did not 
have any prior medical record. Staffs were so rude, but after an insulting argument, I was finally admitted." (Roxana)

\section{Lack of medical knowledge regarding $\mathrm{SCl}$}

When referred to health care centers, a number of participants encountered healthcare providers that were unaware of the unique situation a pregnant woman with SCI.

"I had been waiting for three hours in the queue for sonography, and when I complained that my back hurt, my legs have spasms and I cannot hold my urine, the receptionist did not allow me to cut the line and made me wait longer." (Mona)

Another participant said:

"The midwife bombarded me with many questions such as 'how did you get pregnant?' and 'how could you have sex in this situation?' It was as if they had never seen a pregnant woman with SCI. Moreover, I had been constantly ignored by nurses at the time of discharging from the hospital and after the cesarean when I complained that I need an appropriate toilet." (Leila)

\section{Health professionals' failure to provide adequate information}

A number of participants noted that their obstetricians did not explain the birth procedure and their choice of childbirth delivery method. Most of them had a cesarean section and mentioned they had not received any information about their ability to have a natural childbirth, and noted their inquiries were left unanswered.

"I really wanted to have a natural childbirth, but my doctor did not tell me anything about it. Since the first day, she insisted on cesarean and did not leave any room for an alternative. I just thought that women with SCI can only give birth through cesarean." (Aida)

\section{Inappropriate environment}

All participants talked about the inappropriate condition of toilets in the hospital and non-private conditions.
"The curtains were not fully drawn, and I had no bowel control, so I had to defecate while I was in bed. Given that the other women were healthy, I had to suffer through their looks, and this was very embarrassing for me." (Roxana)

\section{Maternal experience under a supportive umbrella}

All the participants in this study had different forms of support and mentioned the support of their husbands, members of family, and peers.

\section{Support of peers}

All of the participants had conversed with other mothers with SCI. They stated that knowing about the childbirth experience of other women with SCI had reduced their anxiety. In addition, these women benefited from the Association's education materials on childbirth.

"Another woman with SCI, who was a member of the Association, and gave birth after the trauma, helped me a lot. She told me that I should not worry or be afraid." (Aida)

One of the participants, who had a vaginal delivery, had received training in stress management. These self-help techniques for dealing with stress in women with SCI were useful in boosting confidence during the childbirth.

"Before immigrating to Tehran, I was a member of the executive committee of the SCI Association in my city. My colleagues and I invited a gynecologist to the Association to deliver a lecture on childbearing among women with SCI. Later, she became my gynecologist and helped me enormously." (Aida)

\section{Emotional support of husband and others}

The participants reported needing emotional support such as encouragement and praise from their husbands and others in order to deal with stress and anxiety.

"Whenever I was anxious about dealing with many negative thoughts, my husband comforted me and made me feel much better." (Elmira)

"My family encouraged me to have children, and this boosted my mood." (Sara) 


\section{Physical support of husband and others}

The participants stressed the importance of their husbands' support in raising the children.

It should be noted that the husbands of these women were all healthy people, meaning they did not have any physical disability.

"Anytime I had a problem, I would call my husband to come. My husband was always present and helped with the baby's vaccination and immunization or any other medical emergency. Although my relatives were also of great assistance, my husband helped the most." (Aida)

The participants acknowledged the important role and support of their mothers during the first few months after childbirth.

"If my mother had not helped me in bathing, cleaning and dressing the child, I could not do it alone. Nonetheless, we hired a nurse a few months later." (Samira)

\section{Strengthening the spirituality and religious belief}

\section{Will of God and faith}

All participants noted that they had spirituality and religious belief before and after SCI; however, they considered that the will of God has been more effective in their lives and in producing a desired or intended result after childbirth than ever. Moreover, the women with SCI stated that whenever they felt in danger and were concerned about their pregnancy or childbirth, they prayed to God, and trusting in God has helped them in every aspect.

"It was the will of God that I became pregnant, as I had been trying to have a child for years. Even when my water broke and I was concerned that my baby would be stillborn, I trusted in God and prayed for God's help. This made me feel comfortable, and I am grateful that my child is alive." (Roxana)

Moreover, one of the participants considered her concept of childbearing a gift from God:

"I think given that my husband was such a great help to me, God rewarded my husband and gave us this child as a gift." (Susan)

\section{Thanksgiving}

All participants thanked God in different ways after having a baby; by remembering God for his kindness or praying and it was very important to them.

"I always thank God for the baby he gave us. Sometimes, I [also] pray for this." (Mona)

\section{Prayers and making sacred vows}

Both in Iran and the Islamic culture, a common practice is that when people encounter problems they adhere to prayers and making sacred vows. By the same token, due to the difficulties during pregnancy and childbirth, all participants uttered prayers, and a number of them made sacred vows.

"At the early stages of pregnancy, my hips were aching, and I prayed and made a sacred vow. I paid my vow after childbirth." (Elmira)

\section{Discussion}

This study was an attempt to assess the experience of childbearing in women with SCI. The analysis for this study was based on five main themes, including "revivification", "fear and concern of motherhood with SCI", "flawed health care system", "maternal experience under a supportive umbrella", and "strengthening spirituality and religious belief".

This study can be used as a primary source of information on the pregnancy of women with SCI. It could also emphasize the positive aspects of childbearing in the married life of women with SCI.

The feeling of revivification was the main theme that included a feeling of incredible joy, encouragement of life, feeling of equality, improved continuity of marriage, and the completion of marriage by childbearing. These findings were similar to some of the suggested sub-themes by Tebbet and Kennedy [20], which included the unique feeling of happiness, equality, and encouragement to life, which the women with SCI had mentioned during pregnancy and childbirth. Moreover, the importance of support was another sub-theme in their study, and the significance of the husband's support during pregnancy and childbirth was discussed [20].

In the study of Westgren and Levi, it was reported that childbearing stabilized the marital relationship and improved quality of life [28]. In addition, Abbasi-Shavazi et al. in a study on infertility in Iran noted that in Iranian 
culture, childbearing provides the family with security, identity, and pride [4]. These studies were similar to the sub-theme of "the improvement and the continuity of marital relationship" in the present study.

The completion of marriage by childbearing was among the sub-themes in this study. The findings were related to this study, and no similar study found this theme regarding women with SCI, childbearing, and completion of marriage.

In this research, fear and concern have been associated with the process of childbearing in women with SCI. These feelings caused discomfort, crying, and depression, and included the fear of an unhealthy fetus and fear of physical complications during pregnancy. In a study that was conducted by Ghidini et al. [29], women who had children after SCI were more likely to be afraid of pregnancy and raising babies than women with spinal cord injury, who did not yet have children. It seems to need for a biopsychosocial framework for working with women with SCI.

Resentment for inappropriate judgments of others and concerns about motherhood was also among the sub-themes related to the feeling of fear and concern in the present study, and these two findings were located in sub-themes of the importance of support and unique experience in Tebbet's study [20]. The inappropriate judgments of others on miscarriage, concerns of motherhood with disability, and physical defects in the women in the study, had increased their fear and anxiety.

In addition, the flawed health care system was one of the main themes in this study, and with sub-themes of inappropriate professional ethics, the lack of knowledge of health care providers about the appropriate treatment of women with SCI; failure to provide adequate information to women with SCI, the inappropriateness of the health care environment emerged. The malfunctioning health care services system for childbearing in women with SCI could cause physical and mental stress in this group of women. The lack of a dedicated maternity hospital and a professional team familiar with the treatment of women with SCI were among the cases that induced the feeling of being in a problematic health care system.

May et al. mentioned that health care workers must be trained to apply the principles of effective rehabilitation, and it is necessary that the health care professionals be aware of the physical and emotional concerns of people with SCI [30].

The lack of a professional team familiar with the concerns of women with SCI was one of the sub-themes that were mentioned by the participants in the present study.

Tebbet and Kennedy's study was conducted with women who gave birth in a specialized environment [20], which is deemed suitable given the availability of trained experts and special care programs for women with SCI [31]. Hence, their study is different from the current research on the account that all participants in this study gave birth in general maternity hospitals.

The theme of maternal experience under a supportive umbrella included sub-themes of peer support, emotional support of husband and others, physical support of husband and others. These women considered such supports very important. Numerous studies have shown that the support given by husbands, family members, and the medical team plays an important role in the subjective well being and even the quality of life in those with SCI [32].

Strengthening spirituality and religious belief were among other main themes, which have emerged with subthemes of the will of God and faith, thanksgiving, resorting to vows and prayers. After childbearing, most of our participants were thinking about the will of God more than ever and expressed their thanksgiving and appreciation. By the same token, Matheis et al. [33] suggested that spirituality and religion are strong in the life of people with SCI. Since childbearing is a positive event in the point of view of some women with SCI, this strengthened spirituality in their lives is expected [34].

\section{Limitations}

One of the limitations of this study was the diversity in the level of SCI. There were no individuals with tetraplegia represented in the sample of this study. Since different types and levels of SCI might present with different challenges and experiences, some of the findings might not be generalized to a larger population.

Another limitation was that the participants were members of the SCI Association. Perhaps, there are [a few/some] women with SCI in Tehran who had not registered at the SCI Association on the account that they might had been unaware of the existence of the SCI Association, who had a high level of disability, or resided far from the Association. The registered members may have been more aware of selfcare or were well resourced in comparison with the nonmembers.

\section{Implications for practice}

The emerging themes of "fear and concern of motherhood with SCI" and "flawed health care system" in this study showed that there are needs for increasing the public and professional awareness and some clinical considerations. Well-designed interventions are required to dwindle maternal distress in women with SCI and promote their further rehabilitation. In addition, training for improving the clinical knowledge and communication skills of the medical team can have significant outcomes in improving the 
childbearing experience of women with SCI. Finally, selfhelp groups and support groups counseling women with $\mathrm{SCI}$ and their partners before, during and after childbearing can provide hope for a more meaningful future.

Hence, the chief recommendation of the researchers, as supported by the research participants, is launching a specialized center that optimizes the childbearing and childcare experience of women with SCI by offering women with SCI consultation with experts and providing essential medical needs and training.

It appears that the problems associated with women with SCI demand the further attention of the medical team such as nurses, midwives, and obstetricians. Further research on this topic is both necessary and recommended. Each of the emerged themes from this research can be the basis for further studies using different methodologies. This is recommended to better understand the experience of women with SCI during pregnancy and childbirth.

\section{Conclusion}

Childbearing has had a positive impact on family relationships, continuity of marriage, and quality of life. This research uncovers several barriers, that women with SCI face during pregnancy and childbirth. These findings can benefit policymakers in planning and review of regulations to establish a center for childbirth services and counseling for pregnancy and childcare for women with SCI. The need for support (i.e., medical, social, and family support) for these women should be emphasized. There are potential benefits of establishing a center that provides the support necessary to optimize the benefits recognized with childbearing.

Acknowledgements We acknowledge and appreciate the assistance of Mahvash Adib (Director of the SCI Association of Tehran, Iran), Farzad Salimifar (Ministry of Foreign Affairs School of International Relations, Iran), Mahin Nakhshab (Islamic Azad University, Iran), and Effat Sadat Merghati-Khoei (Tehran University of Medical Sciences) to this research project.

\section{Compliance with ethical standards}

Conflict of interest The authors declare that they have no conflict of interest.

Ethical considerations This study has obtained the approval of the Ethics Committee of Tehran University of Medical Sciences. The participants had been informed about the purpose and significance of the research prior to the interviews and had the liberty to answer the questions to their satisfaction. In addition, the participants were permitted to record the interviews, and they were assured that the obtained data would be merely used for research purposes. The participants were also guaranteed that they would withdraw from the interview at any stage.

\section{References}

1. TorkZahrani S. Commentary: childbirth education in Iran. J Perinat Educ. 2008;17:51-54.

2. Fisher C, Hauck Y, Fenwick J. How social context impacts on women's fears of childbirth: a Western Australian example. Soc Sci Med. 2006;63:64-75.

3. Waldenström U, Hildingsson I, Rubertsson C, Rådestad I. A negative birth experience: prevalence and risk factors in a national sample. Birth. 2004;31:17-27.

4. Abbasi-Shavazi MJ, Inhorn MC, Razeghi-Nasrabad HB, Toloo G. The "Iranian ART Revolution" infertility, assisted reproductive technology, and third-party donation in the Islamic Republic of Iran. JMEWS. 2008;4:1-28.

5. Humenick SS. The life-changing significance of normal birth. J Perinat Educ. 2006;15:1.

6. Ayers S, Eagle A, Waring H. The effects of childbirth-related post-traumatic stress disorder on women and their relationships: a qualitative study. Psychol Health Med. 2006;11:389-98. https:// doi.org/10.1080/13548500600708409.

7. Lipson JG. Pregnancy, birth, and disability: women's health care experiences. Health Care Women Int. 2000;21:11-26.

8. Rahimi-Movaghar V, Sayyah MK, Akbari H, Khorramirouz R, Rasouli MR, Moradi-Lakeh M, et al. Epidemiology of traumatic spinal cord injury in developing countries: a systematic review. Neuroepidemiology. 2013;41:65-85.

9. WHO. Spinal cord injury. Geneva: WHO; 2013. http://www.who. int/mediacentre/factsheets/fs384/en/. Accessed 2 Oct 2014.

10. Ashford L. Hidden suffering: disabilities from pregnancy and childbirth in less developed countries. Washington, DC: MEASURE Communication; 2002. p. 6.

11. Khazaeipour Z, Taheri-Otaghsara S-M, Naghdi M. Depression following spinal cord injury: its relationship to demographic and socioeconomic indicators. Top Spinal Cord Inj Rehabil. 2015;21:149-55.

12. Mitra M, Iezzoni LI, Zhang J, Long-Bellil LM, Smeltzer SC, Barton BA. Prevalence and risk factors for postpartum depression symptoms among women with disabilities. Matern Child Health J. 2015;19:362-72. https://doi.org/10.1007/s10995-014-1518-8. PMC4254905

13. Krassioukov A, Warburton DE, Teasell R, Eng JJ, Team SCIRER. A systematic review of the management of autonomic dysreflexia after spinal cord injury. Arch Phys Med Rehabil. 2009;90:682-95.

14. Dawood R, Altanis E, Ribes-Pastor P, Ashworth F. Pregnancy and spinal cord injury. Obstet Gynaecol. 2014;16:99-107.

15. Khazaeipour Z, Ahmadipour E, Rahimi-Movaghar V, Ahmadipour F, Vaccaro A, Babakhani B. Association of pain, social support and socioeconomic indicators in patients with spinal cord injury in Iran. Spinal Cord 2016: 1-7. https://doi.org/10.1038/sc. 2016.160.

16. Russell CK, Gregory DM. Evaluation of qualitative research studies. Evid Based Nurs. 2003;6:36-40.

17. Seymour J, Clark D. Phenomenological approaches to palliative care research. Palliat Med. 1998;12:127-31.

18. Clarke C. An introduction to interpretative phenomenological analysis: a useful approach for occupational therapy research. Br J Occup Ther. 2009;72:37-39. https://doi.org/10.1177/030802 260907200107

19. Lindseth A, Norberg A. A phenomenological hermeneutical method for researching lived experience. Scand J Caring Sci. 2004; 18:145-53.

20. Tebbet M, Kennedy P. The experience of childbirth for women with spinal cord injuries: an interpretative phenomenology analysis study. Disabil Rehabil. 2012;34:762-9. 
21. Seidman I. Interviewing as qualitative research: a guide for researchers in education and the social sciences. 4th ed. New York and London: Teachers College Press; 2013.

22. Agee J. Developing qualitative research questions: a reflective process. Int J Qual Stud Educ. 2009;22:431-47.

23. Sandy QQ, Dumay J. The qualitative research interview. Qual Res Account Manag. 2011;8:238-64.

24. Van Manen M. Researching lived experience: Human science for an action sensitive pedagogy. 2nd ed. London and New York: Routledge; 2016.

25. Golafshani N. Understanding reliability and validity in qualitative research. Qual Rep. 2003;8:597-606.

26. Krefting L. Rigor in qualitative research: the assessment of trustworthiness. Am J Occup Ther. 1991;45:214-22.

27. Lincoln YS, Guba EG. Naturalistic inquiry, Beverly Hills, CA: Sage Publications; 1985.

28. Westgren N, Levi R. Motherhood after traumatic spinal cord injury. Spinal Cord. 1994;32:517-23.
29. Ghidini A, Healey A, Andreani M, Simonson MR. Pregnancy and women with spinal cord injuries. Acta Obstet Gynecol Scand. 2008;87:1006-10.

30. May L, Day R, Warren S. Perceptions of patient education in spinal cord injury rehabilitation. Disabil Rehabil. 2006; 28:1041-9.

31. Bertschy S, Geyh S, Pannek J, Meyer T. Perceived needs and experiences with healthcare services of women with spinal cord injury during pregnancy and childbirth-a qualitative content analysis of focus groups and individual interviews. BMC Health Serv Res. 2015;15:234.

32. Post M, Van Leeuwen C. Psychosocial issues in spinal cord injury: a review. Spinal Cord. 2012;50:382-9.

33. Matheis EN, Tulsky DS, Matheis RJ. The relation between spirituality and quality of life among individuals with spinal cord injury. Rehabil Psychol. 2006;51:265.

34. Linley PA, Joseph S. Positive change following trauma and adversity: a review. J Trauma Stress. 2004;17:11-21. 